\title{
İmmunsüpresif Bir Hastada Herbaspirillum huttiense'nin Etken Oldug̃u Bakteriyemi Olgusu ve Literatür Taraması
}

\section{A Case of Bacteremia Caused by Herbaspirillum huttiense in an Immunosuppressive Patient and Literature Review}

Nurullah UZUNER'(iD), Nezahat AKPOLAT'(ID), Mehmet KUTLAY²(iD)

\footnotetext{
${ }^{1}$ Dicle Üniversitesi Tıp Fakültesi, Tıbbi Mikrobiyoloji Anabilim Dalı, Diyarbakır, Türkiye

${ }^{2}$ Dicle Üniversitesi Tıp Fakültesi, iç Hastalıkları Anabilim Dalı, Diyarbakır, Türkiye
}

Makale atıfi: Uzuner N, Akpolat N, Kutlay M. immunsüpresif bir hastada Herbaspirillum huttiense'nin etken olduğu bakteriyemi olgusu ve literatür taramasI. FLORA 2021;26(1):220-6.

\begin{abstract}
Öz
Herbaspirillum cinsi bakteriler; $\beta$-proteobacteria sınıfında yer alan gram-negatif non-fermentatif basillerdir. Bir kısmı doğada çok sayıda bitkinin üremesini nitrojen fiksasyonu ve fito hormon üretimi yoluyla teşvik eder. Bazı türleri de pirinç fideleri, şeker kamışı gibi bitkiler için patojen olarak bilinen proteobakterilerdir. Yakın zamana kadar endofitik, insan için nonpatojenik bakteriler olarak bilinen Herbasprillum'ların şimdiye kadar 10'dan fazla türü tanımlanmıştır. Insan infeksiyon bölgelerinden ilk izolasyon raporları 1980'li yıllarda yapılmakla birlikte tür tanımlama yöntemlerinin gelişmesine paralel olarak 1996 yılından itibaren Herbasprillum türleri artık özellikle immünsüprese bireylerde infeksiyon ve ölümle ilişkilendirilmektedir. Literatürde sporadik olarak yapılan vaka bildirimleri mevcuttur. Ülkemizden de bildirilen H. huttiense'nin etken olduğu bir vaka mevcuttur ve bu immünkompetan bir hastadır. Bu makalede H. huttiense'nin etken olduğu, akut myeloblastik lösemi tanısılla takipli olup immünsüpresif olan bir hastada gelişen ülkemizdeki ilk bakteriyemi olgusu sunulmuştur.
\end{abstract}

Anahtar Kelimeler: Herbasprillum huttiense; Bakteriyemi; Akut myeloblastik lösemi; immunsüpresyon

\section{ABSTRACT \\ A Case of Bacteremia Caused by Herbaspirillum huttiense in an Immunosuppressive Patient and Literature Review}

Nurullah UZUNER', Nezahat AKPOLAT'1, Mehmet KUTLAY²

\footnotetext{
${ }^{1}$ Department of Medical Microbiology, Dicle University Faculty of Medicine, Diyarbakır, Turkey

${ }^{2}$ Department of Internal Diseases, Dicle University Faculty of Medicine, Diyarbakır, Turkey
}

The bacteria of the genus Herbaspirillum are gram-negative non-fermentative bacilli in the class of $\beta$-proteobacteria. Some promote the reproduction of many plants in nature through nitrogen fixation and phyto hormone production. Some species are proteobacteria,

\begin{tabular}{l|l} 
& Geliș Tarihi/Received: 27/05/2020- Kabul Ediliș Tarihi/Accepted: 12/07/2020 \\
\hline 220 & ${ }^{0}$ Telif Hakkı 2021 Flora. Makale metnine www.floradergisi.org web adresinden ulașilabilir.
\end{tabular}


known as pathogens for plants such as rice seedlings and sugar cane. Until recently, more than 10 species of Herbasprillums, known as endophytic, nonpatogenic bacteria for humans, have been described so far. Although the first isolation reports from human infection sites were made in the 1980s, parallel to the development of species identification methods, Herbasprillum species have been associated with infection and death especially in immunosuppressed individuals since 1996. There are case reports made sporadically in the literature. There is a case of $\mathrm{H}$. huttiense reported from our country and this is an immunocompetent patient. This article presents the first immunosuppressed case of bacteraemia in our country followed by a diagnosis of acute myeloblastic leukemia in which $\mathrm{H}$. huttiense is a factor.

Key Words: Herbasprillum huttiense; Bacteremia; Acute myeloblastic leukemia; Immunosuppression

\section{GiRiș}

Herbaspirillum cinsi $\beta$-Proteobacteria sinifina ait, gram-negatif, non-fermantatif, hareketli, üreaz, oksidaz ve katalaz enzimlerine sahip nitrojen fiksasyonu yapan bakterilerdir. Toprağın rizosfer tabakasından, pirinc, fasulye, seker kamıșı, ananas, muz gibi bitkilerin köklerinden, ayrıca içme suyu dağıtım sistemlerinden, Doğu Asyalı kadınların anne sütünden izole edilmiștir ${ }^{[1,2,4]}$. Daha önceleri bitki büyümesini teșvik eden rizobakterler olarak bilinirken, son zamanlarda bașta kan ve balgam olmak üzere ceșitli klinik materyallerden etken olarak izole edilmeye bașlanmıștır. Klinik materyallerde simdive kadar tanımlanan bașlica türler; Herbasprillum rubrisubalbicans, Herbasprillum seropedicae, Herbasprillum huttiense, Herbasprillum frisingense, Herbasprillum putei $\mathrm{dir}^{[3,5]}$. Mikrobiyoloji laboratuvarlarında kullanıma girmesiyle önemi artan matrix aracilı lazer dezorpsiyonizasyon-ucus zamanı kütlespektrometresi (MALDI-TOF MS) yöntemi ile, diğer otomatize sistemlerle ve geleneksel yöntemlerle identifiye edilemeyen birçok bakteri doğru olarak tanımlanabilmektedir ${ }^{[6]}$. Bu makalede MALDI-TOF MS yöntemi ile tanımladığımız $H$. huttiense'nin etken olduğu, immünsüpresif bir hastada gelișen ülkemizdeki ilk bakteriyemi olgusu sunulmustur. Bu calıșma ile laboratuvarlarda rutin kullanıma giren MALDI-TOF MS yöntemi ile özellikle immünsüpresif hastalarda hızlı ve doğru tanımlama yapılarak mortalite ve morbidetinin azaltılabileceğini vurgulamak istedik.

\section{OLGU SUNUMU}

Akut myeloblastik lösemi (AML) tanisıyla takipli 54 yașinda erkek hasta rutin kontrolleri için bassvurduğu dıs merkeze akut lökoz ön tanısıyla yatırılmıs ve tedavisi düzenlenmiștir. İleri tetkik ve tedavi amaciyla Dicle Üniversitesi Tip Fakültesi Hastanesi Hematoloji Servisi'ne yatıșı yapılmış- tır. AML nedeni ile kemoterapi kürü alan hasta tedavisi devam ederken febril nötropeni tanısı almıstır $\left(38.5^{\circ} \mathrm{C}\right.$ ates ve nötrofil sayısı: $\left.850 / \mu \mathrm{L}\right)$. Vital bulguları stabil olan hastanın öksürük, balgam, boğaz ağrısı, idrarda yanma gibi sikayetleri mevcut değilmiș. Laboratuvar bulgularında, lökosit sayıs1: $1310 / \mu \mathrm{L}$ (4600-10200), nötrofil sayısı: 850/ $\mathrm{LL}$ (2000-6900), prokalsitonin: $0.17 \mathrm{ng} / \mathrm{mL}$ (0-0.12), C-reaktif protein (CRP): $<0.29 \mathrm{mg} / \mathrm{dL}$ (0-0.5) saptand. Tam idrar tetkikinde patolojik bir bulgu yoktu. Hastanın BACTEC Plus Aerobic/F (Becton, Dickinson ABD) siselerine alınan bir set (sağ ve sol koldan olmak üzere) kan kültür örneği BACTEC FX (Becton, Dickinson ABD) cihazında inkübasyona birakıldı. Alınan kan kültürü sonrası hastaya ampirik olarak meropenem 3*1 $1 \mathrm{gr} /$ gün bașlandı. Her iki kan kültürü örneği yaklassık 48 saat sonra pozitif sinyal verdi. Kan kültür sișelerinden hazırlanan gram boyama preparatlarında gram-negatif basiller görüldü. Sisselerden Eozin Metilen Blue (EMB) agar (RTA, Türkiye) ve \%5 Koyun Kanlı agar (KKA) (RTA, Türkiye) besiyerlerine seyreltme yöntemi ile subkültürler yapllp $35 \pm 2{ }^{\circ} \mathrm{C}$ 'de inkübasyona bırakıldı. Yirmi dört saat sonunda $\mathrm{EMB}$ agarda laktozu fermente etmeyen, KKA'da $\mathrm{S}$ tipinde yüzeyden kabarık koloniler üredi (Șekil 1). Koloniler kütle spektrometre MALDI Biotyper 3.1 (Bruker Daltonics, $\mathrm{ABD}$ ) sisteminde $>2.0$ skorla $H$. huttiense olarak tanımlandı (Sekil 2). Taze kültürlerden izolatların biyokimyasal özellikleri konvansiyonel yöntemlerle araștırıld1; sekerleri fermente etmedikleri, üreaz, oksidaz ve katalaz testinin pozitif olduğu gözlendi.

İzolatın, otomatize BD Phoenix 100 sistemiyle (Becton Dickinson, ABD) çalıṣlan antibiyotik duyarlık test (ADT) sonuçları European Committee on Antimicrobial Susceptibility Testing (EUCAST) önerileri doğrultusunda yorumland $(\text { Tablo } 1)^{[7]}$. Literatürde bulunan diğer bazı izolatların ADT 


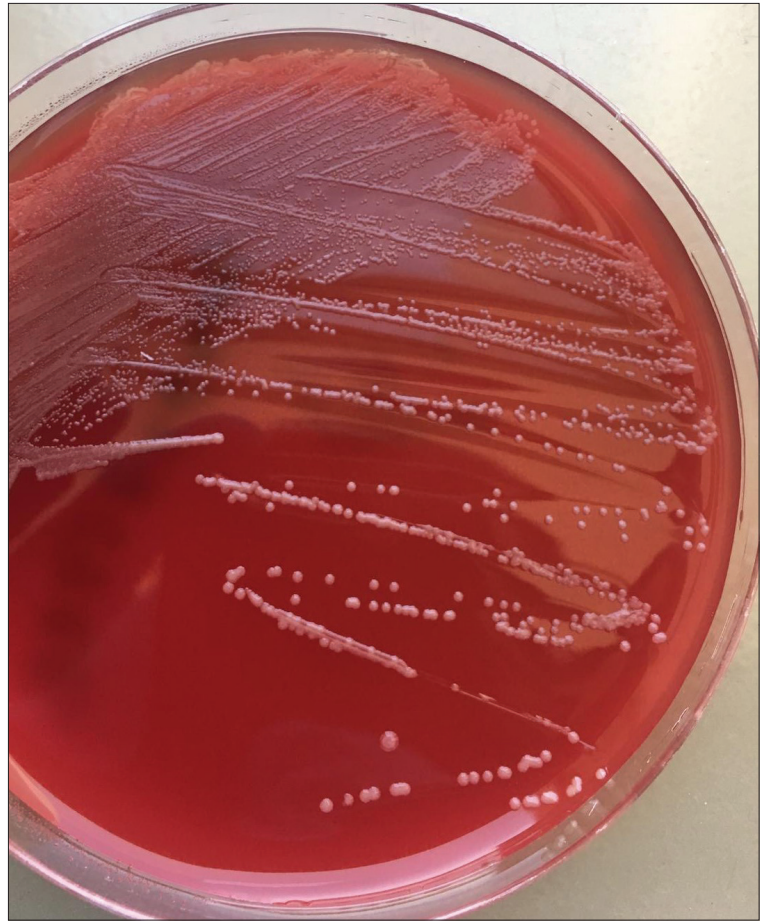

Şekil 1. Bir gecelik inkübasyon sonrasında $\% 5 \mathrm{KKA}$ 'da 's' tipinde $H$. huttiense kolonileri. sonuçları ise Tablo 2'de yer almaktadır. Tedaviye antibiyogram sonucuna göre $H$. huttiense'nin duyarlı olduğu meropenemle devam edildi. Tedavi sonucu genel durumu düzelen, ateși düșen, laboratuvar değerleri normale dönen ve tekrar kan kültürlerinde üremesi olmayan hasta taburcu edildi.

\section{TARTIȘMA}

Yakın zamana kadar sadece doğanın yararlı bakterileri olarak tanımlanan Herbaspirillum'ların, insan infeksiyon etkeni olarak görülmelerini etkileyebilecek nedenlere yönelik cesitli calıșmalar yapılmıstır ${ }^{[5,13]}$. Her ne kadar organizmaya giren veya organizmada bulunan bir mikroorganizma için kesin smirlarla saprofit/patojen/apatojen tanımlaması yapılamazsa bile cesittli gen kazanım ya da kayıplarının bakterilerin virulansı üzerine etkili olabildiği bilinmektedir. Genomların dizilenmesi ve karșılaștırılması, filogenetik çalıșmalar için gücliu bir araç olmustur ve aynı taksonomik grup içindeki cevresel ve fırsatçı (veya patojenik) bakterilerin farklı özelliklerinin aydınlatılmasına yardım etmektedir ${ }^{[14]}$. Araștırmacılar Herbaspirillum'ların

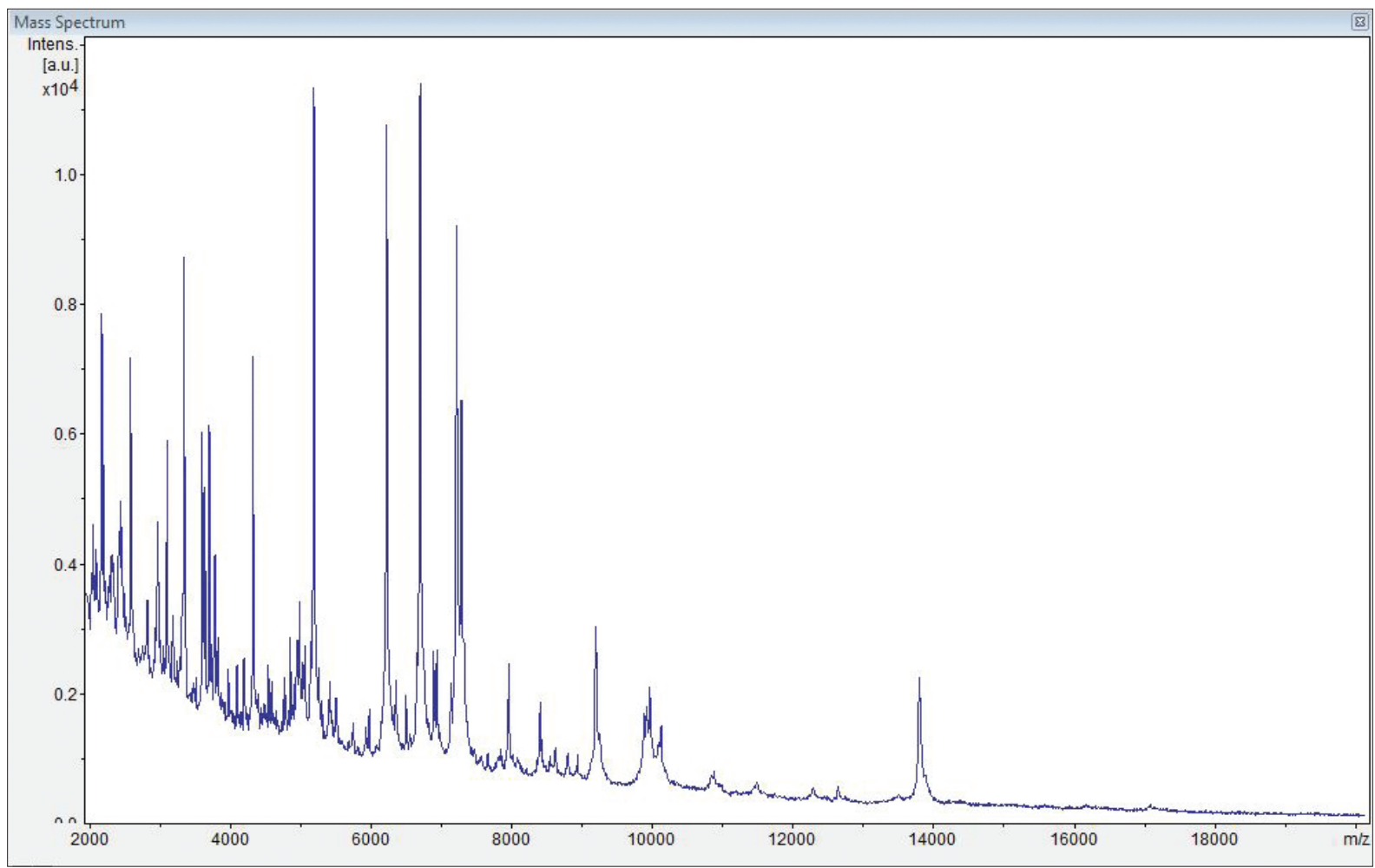

Şekil 2. H. huttiense'nin MALDI Biotyper 3.1 (Bruker Daltonics, ABD) sisteminde saptanan spektrofotometre görüntüsü. 
Tablo 1. İzolatın antibiyotik duyarlıık testi sonuçları

\begin{tabular}{lcc} 
Antibiyotik adı & Mik değerleri (mg/L) & Yorum \\
\hline Ampisilin & $\leq 4$ & $\mathrm{~S}$ \\
Piperasilin-tazobaktam & $\leq 4 / 4$ & $\mathrm{~S}$ \\
Amoksisilin-klavunat & $\leq 2 / 2$ & $\mathrm{~S}$ \\
Seftriakson & $\leq 1$ & $\mathrm{~S}$ \\
Levofloksasin & 2 & $\mathbf{R}$ \\
Siprofloksasin & $>1$ & $\mathbf{R}$ \\
Ertapenem & $<0.25$ & $\mathrm{~S}$ \\
İmipenem & $\leq 0.25$ & $\mathrm{~S}$ \\
Meropenem & 0.25 & $\mathrm{~S}$
\end{tabular}

Tablo 2. Literatürdeki diğer bazı klinik izolatların antibiyotik duyarlılık sonuçları

\begin{tabular}{|c|c|c|c|c|c|c|c|c|c|c|c|c|c|c|c|c|c|}
\hline \multirow[b]{2}{*}{ Hastalar } & \multicolumn{17}{|c|}{ Antibiyotikler } \\
\hline & CAZ & FEP & CRO & AK & GM & ETP & MEM & IPM & COL & SXT & $\mathrm{MH}$ & TZP & CIP & LEV & TOB & $\mathrm{AM}$ & AMC \\
\hline 1. hasta (8) & $\mathrm{S}$ & $S$ & $x$ & $S$ & $\mathrm{R}$ & $x$ & $S$ & $X$ & $x$ & $S$ & $x$ & $S$ & $S$ & $S$ & $S$ & $x$ & $x$ \\
\hline 2. hasta (9) & $X$ & $\mathrm{~S}$ & $X$ & $\mathrm{~S}$ & 1 & $x$ & $X$ & $x$ & $x$ & $S$ & $X$ & $\mathrm{~S}$ & 1 & $x$ & I & $x$ & $X$ \\
\hline 3. hasta (10) & $\mathrm{S}$ & $x$ & $x$ & $X$ & $X$ & $X$ & $\mathrm{~S}$ & $x$ & $\mathrm{R}$ & $\mathrm{S}$ & $\mathrm{S}$ & $X$ & $X$ & $X$ & $X$ & $x$ & $x$ \\
\hline 4. hasta (11) & $\mathrm{S}$ & $\mathrm{S}$ & $x$ & $\mathrm{~S}$ & $S$ & $X$ & $x$ & $\mathrm{~S}$ & $x$ & $S$ & $x$ & S & $\mathrm{S}$ & $\mathrm{S}$ & $\mathrm{S}$ & $x$ & $x$ \\
\hline 5. hasta (12) & $\mathrm{S}$ & $\mathrm{S}$ & $X$ & $\mathrm{~S}$ & $\mathrm{R}$ & $X$ & $x$ & $x$ & $x$ & $x$ & $x$ & $\mathrm{~S}$ & $S$ & $S$ & $x$ & $x$ & $x$ \\
\hline 6. hasta (bizim olgumuz) & $x$ & $x$ & $S$ & $x$ & $x$ & $S$ & $S$ & $S$ & $x$ & $x$ & $x$ & $x$ & $\mathrm{R}$ & $\mathrm{R}$ & $x$ & $S$ & $S$ \\
\hline
\end{tabular}

çevreden insan konakçlara nasıl göc ettiğini daha iyi anlamak için klinik izolatların genomlarını, cevresel izolatların genomları ile karssılaștırmıșlardır ${ }^{[13]}$. Klinik sușların konakçı etkileșimleri ile ilișkili olabilecek yeni genler ve genomik adalar kazandıklarını bildirmișlerdir ${ }^{[13]}$. Klinik sușlarda lipopolisakkarit (LPS) biyosentezi ile ilgili bir gen kümesinin bulunduğunu, çevresel sușlarda yüksek oranda korunmasına rağmen, klinik suștaki LPS biyosentez genlerinin, Herbaspirillum cinsi içinde benzersiz ve ortolog olmayan genler içerdiğini tanımlamıșlardır ${ }^{[13]}$. Aynı araștırıcılar LPS biyosentezinden sorumlu gen kümesinin ayrıca siyalik asit (Neu5Ac) biyosentezinden sorumlu olan genleri de içerdiğini, Neu5Ac bağlantılı LPS'nin, bakterilerin immün sistemden kaçıș yolu olabileceğini belirtmișlerdir. İnvitro bir calıșmada da cevresel ve klinik suṣların biyokimyasal, hemoliz, adezyon gibi özellikleri karșlaștırılmıs, sușlar arasında farklar bulunmamıștır. Sonuc, sușların daha cok bireylerin baskılanmıs immün sisteminden yararlanarak fırsatçı infeksiyona neden olduğu seklinde yorumlanmiștir ${ }^{[5]}$.

Simdiye kadar tanımlanan Herbaspirillum türleri insan infeksiyonlarına nadiren neden olmaktadır. Bu bakteriler coğunlukla malignite gibi immün sistemi baskılayan hastalığı olan kișilerde ve kistik fibrozisli hastalarda fırsatçı infeksiyon etkeni olarak görülmektedir ${ }^{[3,9,15-19]}$. Chemaly ve arkadașları, 2015 yılında kanser hastalarında 8 vakadan olușan Herbaspirillum türlerine ait ilk hastane temelli infeksiyon kümelenmesini bildirmiștir $^{[19]}$. Spilker ve arkadașları 28 kistik fibrozisli hastanın değerlendirildiği bir çalıșmada 27 hastanın solunum yolu örneğinden ve bir hastanın kan örneğinden Herbesprillum ( $H$. rubrisubalbicans, $H$. seropedicae, $H$. putei, $H$. huttiense, $H$. frisingense) türlerini tanımlamayı bașarmıșlardır ${ }^{[3]}$. Bașka 
bir çalıșmada esansiyel trombositopeni ile takip edilen ve immün sistemi hakkında net bilgiye sahip olunmayan 59 yașında kadın hastanın balgam kültuiründe $H$. hutteinse/Herbasprillum aquaticum tanımlanmıștır ${ }^{[11]}$. Olgumuz bildiğimiz kadarıyla ülkemizde immün sistemi baskılanmıs bir hastada Herbasprillum cinsine ait bildirilen ilk infeksiyon vakasıdır. Bunların dıșında immünkompetan hastalardan izole edilen Herbasprillum'a bağlı gelișen münferit infeksiyon olguları da bildirilmiștir ${ }^{[8,12]}$. İmmünkompetan bir kiside tanımlanlanan ilk Herbasprillum ( $H$. aquaticum/H. huttiense) olgusu 2015 yılında bildirilen bakteriyemi ve pnömonili bir hastadir ${ }^{[8]}$. Ülkemizde ise Alzheimer tanısı ile takipli immünkompetan bir hastada $H$. huttiense'ye bağlı gelișen bakteriyemi tablosu bildirilmiștir ${ }^{[12]}$. Mevcut literatür bilgilerimize göre insanlarda infeksiyon olusturan Herbasprillum türleri kan ve solunum yolu örnekleri ön planda olmak üzere; bacak yaraları, göz, kulak, diz eklemi, idrar yolu, gastrointestinal sistem, aort anevrizmasının arteriyel duvarı gibi cok ceșitli klinik materyallerden izole edilmiștir ${ }^{[8,18-20,22]}$.

Herbasprillum türleri filogenetik ve fenotipik benzerlikleri nedeniyle otomatize sistemlerde Burkholderia cepacia complex (BCC) (daha sik olarak), Cupriavidus pauculus ve Ochrobactrum anthropi olarak yanlıs tanımlanmaktadır. BD Phoenix, MicroScan ve Vitek2 gibi bakteriyel tanımlama icin yaygın olarak kullanılan otomatize sistemlerin veri tabanında Herbaspirillum türleri yer almamaktadir. Bu nedenle, Herbasprillum'u tanımlamak için veritabanında Herbasprillum türlerinin olmadığı otomatize sistemler kullanılamaz. Geleneksel tanımlama yöntemleri ise Herbasprillum'u cins düzeyinde tanımlamak için yeterli olmamaktadır ${ }^{[1-3,8,17-21]}$. Herbaspirillum türleri ile ilgili literatürde sınırlı sayıda vaka bulunması bu yanlıș tanımlanmaya bağlanmıștır ${ }^{[23]}$. Herbasprillum türleri Burkholderia cepacia complex ile benzer olarak hareketli, katalaz, oksidaz, üreaz aktivitelerine sahip gram-negatif non-fermentatif basillerdir. Bu nedenle rutin uygulanan konvansiyonel laboratuvar yöntemleri ile ayrımları yapılamamaktadır. Herbaspirillum türlerinin antibiyotik duyarlılı profilleri ise BCC'ye göre farklıdır. Bu bilgiler 1 șı̆̆ında otomatize sistemler tarafından tanımlanan nadir görülen laktozu fermente etmeyen gram-negatif bakteriler, antibiyotiklerin tamamına veya çoğuna duyarlı ise bu mikroorganizma için yanlıs tanımlamadan süphelenilmelidir ve diğer tanımlama yöntemleriyle doğrulanmalıdır ${ }^{[9,11]}$. Spilker ve arkadaşları Micro Scan, Rapid NF, Vitek, API NF, Phoenix, Biochem sistemleriyle 28 izolatın 19 tanesini Burkholderia cepacia complex, 4 tanesini Ralstonia spp. olarak tanımlamıșlardır. Bes izolatı tanımlayamamıșlardır[3]. Liu ve arkadașları bir izolatı VITEK 2 sistemi ile BCC olarak tanımlarken; aynı izolatı MALDI-TOF MS yöntemi ile $H$. hittuense olarak identifiye etmișlerdir ${ }^{[10]}$. Suwantarat ve arkadașları BD Phoenix ile üc izolatı Cupriavidus pauculus ve Burkholderia cepacia kompleksi olarak identifiye etmișlerdir. Aynı etkenler gaz-sıvı kromatografisi ile yapılan hücre duvarı yağ analizi ile Herbasprillum spp. ve MALDI-TOF MS ile $H$. huttiense olarak tanımlanmıstır ${ }^{[9]}$. Calıșmalarda referans yöntem olarak 16S rRNA gen sekanslama metodu kullanılmıștır ${ }^{[3,8-11]}$. Ülkemizde Aslaner ve arkadașları tarafindan bildirilen bir vakada immünkompetan bir hastanın kanında $H$. huttiense etkeni MALDI-TOF MS ile tanımlanmıș ve sekanslamaya gerek duyulmamıstır [12]

MALDI-TOF MS hizlı tanımlama oranı ve yüksek ayırıcı gücü ile nadiren insan patojenleri olarak bildirilen ve rutin yöntemler kullanılarak tanimlanması zor olan mikroorganizmaların identifiye edilebilmesi için yararlı bir aractır ${ }^{[6]}$. MALDI-TOF MS, geleneksel fenotipik yöntemler ve moleküler tanımlamalar ile karșılaștırıldığında nadiren insan patojenleri olarak bildirilen Burkholderia cepacia complex ve diğer bakteri türlerini tanımlayabilir (8). Yapılan calıșmalara göre Herbasprillum türlerini içeren kapsaml bir veri tabanına sahip MALDI Biotyper veri tabanını içeren bir Microflex cihazı kullanılarak yapilan kütle spektrometresi yöntemi ile Herbasprillum'lar cins düzeyinde tanımlanabilmektedir ${ }^{[9-11]}$. Moleküler tanımlama teknikleri ise mikroorganizmaları tanımlamada en faydalı yöntemdir. $H$. huttiense ve $H$. aquaticum türlerini ayırt etmek, 16S rRNA geninin sekans bazl tanımlamasıyla mümkündür ${ }^{[8,23]}$. Biz de iki kan kültürü örneğinden izole ettiğimiz sușları MALDI Biotyper (Bruker Daltonics, ABD) ile tiplendirdik. Biyokimyasal özellikleri $H$. huttiense'yi desteklediŏi ve literatürde de kullanılan kütle spektrometre yönteminin gen sekanslama ile uyumlu sonuçları 
olduğundan moleküler yöntemlere gerek duymadık.

Sonuc olarak MALDI-TOF MS yönteminin mikrobiyoloji laboratuvarlarında rutin olarak kullanıma girmesi ile insanda nadiren infeksiyonlara neden olan mikroorganizmaların tanımlaması hızlanmıștır. İmmünsüpresif hastalarda, nadiren insan patojeni olarak tespit edilen bakteriler kolayllkla infeksiyona neden olabilmektedir. Otomatize tanımlama sistemlerinin ülkemizde bulunan tüm laboratuvarlara kazandırılması özellikle immünsüpresif hastalarda infeksiyona neden olan etkenlerin hızlı ve doğru tanımlanmasını sağlayacaktır. Böylece morbidite ve mortalitenin azaltılabileceğini düșünüyoruz.

\section{ÇIKAR ÇATIȘMASI}

Yazarlar bu makale ile ilgili herhangi bir cıkar catıșması bildirmemișlerdir.

\section{YAZAR KATKISI}

Anafikir/Planlama: NU

Analiz/Yorum: NU, NA, MK

Veri sağlama: NU, MK

Yazım: NU, NA, MK

Gözden Geçirme ve Düzeltme: NU, NA

Onaylama: NU, NA, MK

\section{KAYNAKLAR}

1. Chen L, Jia RB, Li L. Bacterial community of iron tubercles from a drinking waterdistribution system and its occurrence in stagnant tap water. Environ Sci Process Impacts 2013;15(7):1332-40.

2. Li SW, Watanabe K, Hsu CC, Chao SH, Yang ZH, Lin YJ, et al. bacterial composition and diversity in breast milk samples from mothers living in Taiwan and Mainland China. Front Microbiol 2017;8:965.

3. Spilker T, Uluer AZ, Marty FM, Yeh WW, Levison JH, Vandamme $P$, at al. Recovery of Herbaspirillum species from persons with cystic fibrosis. J Clin Microbiol 2008;46(8):2774-7.

4. Breidenbach B, Pump J, Dumont MG. Microbial community structure in the rhizosphere of rice plants. Front Microbiol 2016;6:1537.

5. Marques $A C$, Paludo KS, Dallagassa $C B$, Surek $M$, Pedrosa $F O$, Souza EM, et al. Biochemical characteristics, adhesion, and cytotoxicity of environmental and clinical isolates of Herbaspirillum spp. J Clin Microbiol 2015;53(1):302-8.

6. van Belkum A, Chatellier S, Girard V, Pincus D, Deol P, Dunne WM Jr. Progress in proteomics for clinical microbiology: MALDI-TOF MS for microbial species identification and more. Expert Rev Proteomics 2015;12(6):595-605.
7. EUCAST. European Committee on Antimicrobial Susceptibility Testing Breakpoint Tables for Interpretation of MICS and Zone Diameters- Version 9.0.; 2019. Erişim Tarihi: 12.05.2020. Available from: https://www.eucast.org/ fileadmin/src/media/PDFs/EUCAST_files/Breakpoint_tables/v_9.0_Breakpoint_Tables.pdf

8. Regunath $H$, Kimball J, Smith LP, Salzer W. Severe community-acquired pneumonia with bacteremia caused by Herbaspirillum aquaticum or Herbaspirillum huttiense in an immune-competent adult. I Clin Microbiol 2015;53(9):3086-8.

9. Suwantarat N, Adams LL, Romagnoli M, Carroll KC. Fatal case of Herbaspirillum seropedicae bacteremia secondary to pneumonia in an end-stage renal disease patient with multiple myeloma. Diagn Microbiol Infect Dis 2015;82(4):331-3.

10. Liu C, Kwon MJ, Kim M, Byun JH, Yong D, Lee K. Septicemia caused by Herbaspirillum huttiense secondary to pneumonia. Ann Lab Med 2019;39:340-2.

11. Abreu-Di Berardino M, Rodríguez-Czaplicki E, Sánchez-Hellín V. Herbaspirillum huttiense pneumonia in a patient with essential thrombocythaemia. Rev Esp Quimioter 2019;32(1):83-84.

12. Aslaner H, Kılıçaslan N, Yılmaz N, Akınaı E, Bodur H. Immünkompetan bir hastada Herbaspirillum huttiense bakteriyemisi. Turkiye Klinikleri J Intern Med 2018;3(2):77-80.

13. Faoro $H$, Oliveira WK, Weiss VA, Tadra-Sfeir MZ, Cardoso $R L$, Balsanelli $E$, et al.Genome comparison between clinical and environmental strains of Herbaspirillum seropedicae reveals a potential new emerging bacterium adapted to human hosts. BMC Genomics 2019;20(1):630.

14. Palmer M, Steenkamp ET, Coetzee MPA, Blom J, Venter SN. Genome-based characterization of biological processes that differentiate closely related bacteria. Front Microbiol 2018;9:113.

15. Coenye T, Goris J, Spilker T, Vandamme P, Li Puma JJ. Characterization of unusual bacteria isolated from respiratory secretions of cystic fibrosis patients and description ofInquilinus limosus gen. nov., sp. nov. I Clin Microbiol 2002;40(6):2062-9.

16. Chen J, Su Z, Liu Y, Sandoghchian S, Zheng D, Wang S, et al. Herbaspirillum species: a potential pathogenic bacteria isolated from acute lymphoblastic leukemia patient. Curr Microbiol 2011;62(1):331-3.

17. Tan MJ, Oehler R. Lower extremity cellulitis and bacteremia with Herbaspirillum seropedicae associated with aquatic exposure in a patient with cirrhosis. Infect Dis Clin Pract 2005;13(5):277-9.

18. Ziga ED, Druley T, Burnham CA. Herbaspirillum species bacteremia in a pediatric oncology patient. I Clin Microbiol 2010;48(11):4320-1.

19. Chemaly RF, Dantes $R$, Shah DP, Shah PK, Pascoe N, Ariza-Heredia $E$, et al. Cluster and sporadic cases of herbaspirillum species infections in patients with cancer. Clin Infect Dis 2015;60(1):48-54. 
20. Baldani JI, Pot B, Kirchhof G, Falsen E, Baldani VL, Olivares $F L$, et al. Emended description of Herbaspirillum; inclusion of [Pseudomonas]rubrisubalbicans, a milk plant pathogen, as Herbaspirillum rubrisubalbicans comb. nov.; and classification of a group of clinical isolates (EF group 1) as Herbaspirillum species 3. Int J Syst Bacteriol 1996;46(3):802-10.

21. Marques AC, Paludo KS, Dallagassa CB, Surek M, Pedrosa FO, Souza EM, at al. Biochemical characteristics, adhesion, and cytotoxicity ofenvironmental and clinical isolates of Herbaspirillum spp. J Clin Microbiol 2015;53(1):302-8.

22. Silva RM, Caugant DA, Eribe ERK, Aas JA, Lingaas PS, Geiran O, at al. Bacterialdiversity in aorticaneurysmsdeterminedby 165 ribosomal RNA gene analysis. J Vasc Surg 2006;44(5):1055-60.
23. Baldani JI, Baldani VLD, Seldin L, Döbereiner J. Characterization of Herbaspirillurn seropedicae gen. nov. sp. nov. a root-associated nitrogen-fixing bacterium. Int J Syst Bacteriol 1986;36:86-93.

\section{Yazıșma Adresi/Address for Correspondence}

Asistan Dr. Nurullah UZUNER

Dicle Üniversitesi Tıp Fakültesi,

Tibbi Mikrobiyoloji Anabilim Dalı,

Diyarbakır-Türkiye

E-posta: nurullahuzuner38@gmail.com 